\title{
DIREITO ADQUIRIDO AO REGIME DE APOSENTADORIA
}

\author{
VALMIR PONTES FILHO
}

O princípio da segurança das relaçōes jurídicas, o direito adquirido e a expectativa de direito $-O$ novo regime de aposentação dos servidores públicos

O princípio da segurança das relações jurídicas, o direito adquirido e a expectativa de direito

O princípio da segurança das relações jurídicas e a obrigatória submissão de todos, governantes e governados, à lei e à jurisdição, constituem o substrato do chamado Estado Democrático de Direito. De regime democrático de governo, afinal, só se pode falar quando a ordem normativa tem origem popular, quando a vontade da lei prevalece sobre a dos administradores e, principalmente, quando o próprio organismo estatal se sujeita, tanto quanto os cidadãos comuns, às decisões judiciais. Numa democracia, dos órgãos governativos o que se espera é uma conduta exemplar, mesurosa à lei, à moralidade, à isonomia e, notadamente, aos interesses da coletividade, bem mais valiosos do que os do Erário. Não é demasiado lembrar, além disso, que não pode haver progresso, notadamente social e econômico, sem permanência e estabilidade das relações jurídicas. Nem que nenhum país do mundo avançou, social e tecnologicamente, sem que a liberdade e a democracia estivessem garantidas por uma ordem jurídica estável, infensa aos caprichos dos eventuais "detentores do poder" (que, na verdade, não passam de meros exercentes de competências juridicamente definidas).

Cabe, neste embalo, refletir sobre o verdadeiro conteúdo e alcance do instituto do direito adquirido, em confronto com o que se convencionou chamar de expectativa de direito, já que o respeito àquele se mostra essencial à mantença da segurança jurídica. Parece imprescindível revisitar o tema, dantes enxergado sob prisma exclusivamente civilístico, para dele extrair conclusões novas, compatíveis com a sistemática do Direito Público. 
Romper ou mesmo modificar, unilateralmente, seja por amor a dogmas ou concepções doutrinárias estratificadas, seja em nome de suposto "interesse público", a natureza de relações que se estabelecem, em dado tempo, por força de lei (no sentido lato da expressão), é ou não possível, desde que esse rompimento ou modificação se opere por lei nova? A resposta a essa indagação não pode ser dada, segundo nosso pensar, senão depois de considerados aspectos relevantes, que defluem do já invocado princípio da segurança das relações jurídicas ${ }^{1}$, sem o qual sequer se pode pensar em convivência social harmônica e civilizada.

Talvez seja hora de admitir que determinadas relações jurídicas, uma vez estabelecidas (legal ou contratualmente), não podem ser objeto de ataques, de modo a atingir (alterando-as) as condições para a plena fruição ou utilização futura, por uma das partes, do direito (já adquirido). Assim - a não ser que haja concordância por parte de ambos os pólos da relação - não nos parece admissível a modificação, para torná-los de atingimento mais difícil ou oneroso, dos pressupostos originariamente fixados para o exercício do direito. Este, enfim, já está outorgado, estando apenas o seu exercício pleno dependente de requisitos a serem cumpridos e que não podem, repita-se, ser outros senão os ditados quando do estabelecimento da dita relação jurídica.

Em dadas situações, portanto, aquilo que se imaginava ser mera expectativa, já é, com efeito, um direito adquirido, cuja mera fruição, repita-se, depende da satisfação das condições preestabelecidas.

\section{O novo regime de aposentação dos servidores públicos}

Com o escopo de promover significativa alteração no sistema de previdência social até então em vigor, restou editada a Emenda Constitucional $n^{\circ} 20$, por via da qual vários dos dispositivos na Lei Magna de 1988 sofreram modificações e/ou acréscimos substanciais.

Por via dessa Emenda instituiu-se regime de previdência de caráter contributivo, observados critérios que preservassem o seu equilíbrio financeiro e atuarial (art. 40 da Constituição, já com a nova roupagem). A partir daí, não só no âmbito da União como no das demais pessoas políticas integrantes da federação, desencadeouse processo de aprovação de diplomas legais visando à criação de "sistemas únicos de previdência" (organizado "com base em normas gerais de contabilidade e atuária, de modo a garantir seu equilíbrio financeiro a atuarial"), ao qual se deveriam vincular, obrigatoriamente, todos os servidores titulares de cargos efetivos, inclusive os das autarquias e fundações e os membros da Magistratura. (art. $6^{\circ}, \S 2^{\circ}$, da EC $\left.n^{\circ} 20\right)$.

Os servidores públicos se viram, demais disso, submetidos a novo regime de contagem de tempo (agora de contribuição à previdência e não de mais de serviço

1 De que são manifestações pontuais os institutos do direito adquirido, da coisa julgada e do ato jurídico perfeito. 
público, como dantes) para a aposentadoria, vedando-se-lhes ainda a contagem de "tempo ficto" (de período de férias não gozadas em dobro, v.g.). Passaram a surgir, então, dúvidas diversas, notadamente quanto ao verdadeiro regime de aposentação dos servidores públicos em atividade, tivessem ou não eles satisfeito os novos requisitos constitucionais para a aposentadoria: teriam tais servidores, diante da novel normatização constitucional e legal da matéria, o direito assegurado à percepção de proventos integrais e a pensões, a teor de anteriores? A que contribuição previdenciária estariam os servidores hoje sujeitos?

A resposta a tais indagações exige hábil consideração do papel das emendas constitucionais na ordem jurídico-constitucional, assim como sobre a prevalência dos direitos adquiridos perante elas. Aceitando a tese de que as emendas constitucionais não têm o condão de desconstituir esses direitos, Celso Antônio BANDEIRA DE MELLO chega a afirmar "... que a pretexto de efetuar Emendas Constitucionais, o legislador ordinário - que não recebeu mandato constituinte e cuja posição é juridicamente subalterna - poderia, inclusive, em comportamento "de fato", não jurídico, derrocar a Constituição, por si mesmo ou tangido por algum caudilho, travestido ou não de democrata... Diante de evento de tal natureza, as medidas que fossem impostas perderiam o caráter de Emendas. Converter-se-iam, elas próprias, em novo exercício do Poder Constituinte, tal como ocorreria após revoluções ou golpes de Estado... É claro, entretanto, que nas situações desse jaez estaria rompida a ordem constitucional vigente e inaugurada outra" ${ }^{2}$.

É induvidoso que a ofensa aos institutos do ato jurídico perfeito, direito adquirido e da coisa julgada importa a derruição dos princípios da irretroatividade das leis e da segurança jurídica e, com ele, do próprio Estado Democrático de Direito. À lei, portanto, definitivamente não é dado retroagir para prejudicar os atos jurídicos perfeitos, os direitos adquiridos e as coisas julgadas (Constituição, art. $5^{\circ}, \mathrm{XXXVI).}$ De retroação só se pode cogitar em relação à lei penal, quando esta for mais benéfica ao réu (CF, art. $\left.5^{\circ}, \mathrm{XL}\right)$.

Não discordando, Alexandre de MORAES, cuja lucidez no trato do tema é digna de louvor, cita BASTOS para lembrar que “... a utilização da lei em caráter retroativo, em muitos casos, repugna porque fere situações que já se tinham por consolidadas no tempo e esta é uma das fontes principais da segurança do homem na terra" ${ }^{3}$. Sem desvio de rumo está o pensamento de Ivo DANTAS ${ }^{4}$. Cabe, então,

2 "Curso de direito administrativo", $11^{2}$ ed., Malheiros, São Paulo, 1999, p.212.

3 "Direito constitucional", Atlas, $7^{2}$ ed., p.99. Do mesmo autor a lembrança de que "... a Lei Magna prevê, expressamente, seguindo a tradição constitucional, a imutabilidade das cláusulas pétreas (art. $60, \S 4^{\circ}, \mathrm{IV}$ ), ou seja, a impossibilidade de emenda constitucional prejudicar os direitos e garantias individuais, entre eles, o direito adquirido (art. $5^{\circ}, \mathrm{XXXVI).} \mathrm{Todos} \mathrm{os} \mathrm{aposentados} \mathrm{e}$ pensionistas, portanto, possuem direito adquirido, não só em relação à existência da aposentadoria, como situação jurídica já concretizada, mas também em relação aos valores e regras de atualização dos proventos recebidos, regidos pela constituição e legislação atuais, inatacáveis por meio de proposta de emenda constitucional... aqueles que já preencheram todos os requisitos exigidos para a aposentadoria, na vigência da Constituição e da legislação atuais, porém continuam a exercer, 
aplicar aqui o que antes se disse sobre o verdadeiro conteúdo e alcance do instituto do direito adquirido, em confronto com o que se convencionou chamar de expectativa de direito.

Nesta última hipótese, a da simples expectativa, afirma a doutrina tradicional que “... não se compôs o ciclo constitutivo do núcleo essencial da incidência da regra jurídica, ou, noutros termos, a fatispécie abstrata, que tem aspecto declaratório, não coincide com a fatispécie concreta" ... não passando de "... uma realidade pré-jurídica, vinculada a uma situação de fato ou de direito que ainda não atingiu sua maturidade". Já quando se alude a direito adquirido, vê-se que "... já se perfez a integração do mundo fático ao jurídico" 5 . O entendimento clássico, com efeito, é o de que este último vem a ser "... a conseqüência de uma lei, por via direta ou por intermédio de um fato idôneo", enquanto a expectativa de direito é "... a faculdade jurídica abstrata ou em vias de concretizar-se, cuja perfeição está na dependência de um requisito legal ou de um fato aquisitivo específico", residindo a diferença entre uma e outro "... na existência, em relação a este (direito adquirido), do fato aquisitivo específico, já configurado por completo" ${ }^{\text {. }}$.

Não se discute, assim, pelo que já ficou exposto, que o servidor público - para aproveitar o exemplo do Prof. Alexandre de MORAES - tem direito adquirido à aposentação e à fixação dos seus proventos segundo as regras constitucionais e legais vigentes no momento em que adquiriu ele o direito a essa aposentadoria, direito esse infenso quer à lei, quer à emenda constitucional supervenientes. Induvidoso, também, que a ele é dado ter como definitivamente incorporadas ao seu patrimônio as vantagens a cuja percepção proporcional haja adquirido o direito, de acordo com o seu tempo de serviço.

A questão é outra, mais delicada: pode a nova lei (ou a nova emenda à Constituição) alterar, para torná-los de atingimento mais difícil, os requisitos dantes fixados para a concessão da aposentadoria? Ou, em outras palavras: se, por exemplo, em momento anterior, um servidor do sexo masculino podia aposentar-se, com proventos integrais, aos trinta e cinco anos de serviço público, essa condição fática pode vir a ser alterada a posteriori, de modo a alcançar quem ainda não satisfez esse requisito dantes estabelecido?

A resposta comumente dada é positiva, pois esse servidor, uma vez não tendo ainda satisfeito o requisito temporal (de índole constitucional, no caso) para a aposentação, apenas seria portador de uma expectativa de direito, de um "direito a se formar" (um "ver-a-ser" jurídico). Inocorrido o fato específico previsto na norma

suas funções, têm a garantia do direito adquirido, não só, repetimos, em relação à aposentadoria, como também que seus proventos da inatividade regular-se-ão pela legislação vigente ao tempo em que reuniram os requisitos necessários" (Súmula 259 do STF) - ob. cit., ps. 100/101.

4 "Direito adquirido, emendas constitucionais e controle da constitucionalidade", Lumen Juris, Rio de Janeiro, 1997, ps. 55/62.

5 Érito MACHADO, “A retroatividade da norma constitucional”, Ed. Salvador, $2^{\mathbf{a}}$ ed., p.37.

6 Limongi FRANÇA, “A irretroatividade das leis e o direito adquirido”, 4a. ed., RT, São Paulo, 1982, ps. 240/241. 
(os trinta e cinco anos de serviço), inexistiria, conseqüentemente, o direito adquirido à aposentação. Imagine-se, todavia, a seguinte situação (adotado o pressuposto de que, inexistindo a aquisição do direito, as regras disciplinadoras da aposentadoria possam ser modificadas por emenda constitucional): contando 34 anos de serviço, um dado funcionário se vê surpreendido por emenda que prorroga o tempo bastante à inatividade para 40 anos (outrora 35 , como visto); se uma primeira prorrogação fosse possivel, a consequiência lógica seria a de que outras sucessivas também seriam viáveis. Eis que, completados 39 anos de serviço, uma segunda emenda cuidaria de fixar o mínimo de 45 anos de labor para a inativação. Uma terceira, por sua vez, trataria de estipular um mínimo de 50 anos de serviço até que, de emenda em emenda, uma última alteração normativa asseguraria ao servidor o direito de aposentar-se quando de sua próxima reencarnação.

Dir-se-á, possivelmente, que o argumento é absurdo, desarrazoado, ad terrorem, senão tragicômico. Mas ele serve, ao menos, para que se cogite da possibilidade exatamente para evitar situações bizarras como esta - de existência de direito adquirido a um dado regime de aposentação, fixados pelas normas (constitucionais e/ou legais) vigentes no exato instante em que o servidor ingressa no serviço público. Esse entendimento - embora (ainda) não aceito pela doutrina - privilegia, a desdúvidas, a segurança jurídica, na medida em que dá a cada servidor a certeza de que pode projetar sua vida futura, afastando-se do cargo ou emprego público na época precisa que a lei (lato sensu) estipulou como suficiente para tanto. Esta certeza (e não mera "expectativa") lhe dará, além de conforto psicológico, o senso perfeito de que, uma vez cumprido aquele lapso temporal (de serviço público, de contribuição à previdência ou outro qualquer), a sua inativação não poderá ser obstaculizada pela obra do legislador infraconstitucional (é dizer, por lei ou emenda). Não se trataria, pois, de mera "aspiração" ou "desejo", mas de direito adquirido sim, a uma dada previsão normativo-jurídica que se incorporou ao seu patrimônio pessoal. Afinal, se o servidor fez, em dado momento, uma opção de vida profissional, é imperioso conferir-lhe, em homenagem à sua própria dignidade, a prerrogativa de traçar planos para o futuro, especialmente após a inativação almejada.

O que não pode o Poder Público é alterar, a seu talante e alvedrio — por "lei de ordem pública" ou em nome de um alegado "interesse público" (secundário, ou seja, da própria Administração, e às vezes meramente contingencial) - as condições previstas no sistema jurídico para a aposentação do servidor, de forma a alcançá-lo a meio caminho da inativação. Se pudesse, ferido de morte restaria um interesse público primário, qual o de ver-se preservada a segurança das relações jurídicas, inclusive e principalmente as que se estabelecem (por lei ou diretamente pela Constituição) entre a Administração e os administrados (entre estes, os servidores públicos). Incabível supor que a "ordem pública" agasalhasse tal hipótese. As modificações e alterações haveriam de surtir efeitos, assim, tão-só em relação aos que viessem a ter ingresso no serviço público após a edição das novas regras, jamais retroativamente. Em socorro dessa idéia nos valemos da sempre precisa palavra de CELSO ANTÔNIO: "Esta segurança jurídica coincide com uma das mais profundas aspiraçōes do Homem: a da segurança em si mesmo, a da certeza possivel em relação ao que o cerca, sendo esta uma busca permanente do ser humano. É a insopitável 
necessidade de poder assentar-se sobre algo reconhecido como estável, ou relativamente estável, o que permite vislumbrar com alguma previsibilidade o futuro; é ela, pois, que enseja projetar e iniciar, conseqüentemente - e não aleatoriamente, ao mero sabor do acaso - comportamentos cujos frutos são esperáveis a médio e longo prazo. Dita previsibilidade é, portanto, o que condiciona a ação humana. Esta é a normalidade das coisas" ${ }^{7}$. Não se está aqui defendendo - é bom esclarecer a tese de que haja, de modo irrestrito, direito adquirido do servidor público a um dado regime jurídico. Nada obsta, por exemplo, que a carreira a que pertença seja reestruturada, que seu horário de trabalho se modifique para atender ao interesse público ou mesmo que gratificações que perceba sejam modificadas ou extintas (desde que respeitada a irredutibilidade remuneratória que a Constituição lhe assegura). Referimo-nos, especificamente, ao regime jurídico previsto para a sua aposentadoria, essencial para que ele possa programar, com um mínimo de certeza e segurança, sua própria existência futura.

Esta é uma posição que reconhecemos ousada, mas não desprovida de fundamento. Tanto é que um ante-projeto de Código Civil, elaborado ainda em 1897 por COELHO RODRIGUES, entendia serem direitos adquiridos “... não só os direitos que o titular ou alguém por ele já pode exercer, como aqueles cujo exercício depende de prazo prefixado ou condição preestabelecida e não alterável ao arbitrio de outrem". Mais de um século depois, é de reconhecer-se o acerto da propositura, bastando, hoje, que se entenda por "outrem" também o Estado.

À luz dessas reflexões, somos forçados a concluir que as novas regras atinentes à aposentação, embora veiculadas por emenda constitucional, só se aplicam para os que hajam ingressado no serviço público a partir de sua vigência da EC/20. Assim, cabe concluir, resumidamente:

- em relação ao servidor que, à data da promulgação da $\mathrm{EC} / 20$, já haja cumprido os requisitos para a aposentadoria fixados pelas normas constitucionais e legais então vigentes, é certo que, tendo adquirido o direito à aposentação - não importando se esta já formalmente se concretizou - a ele não se aplicam as novas exigências estabelecidas pela referida Emenda (tal seria assim mesmo que a EC/20 não o houvesse dito no seu art. $3^{\circ}$ e parágrafos), quer as atinentes a tempo de serviço e/ou contribuição, quer as relativas à obrigatoriedade de voltar a contribuir para o sistema previdenciário; intocado, demais disso, permanece o seu direito à percepção de proventos integrais, correspondentes sempre à remuneração do cargo em que se aposentou (ou se aposentará); igualmente íntegro remanesce o direito à pensão fixada nos termos da legislação em vigor à época do eventual falecimento do contribuinte;

- quanto ao servidor que ainda não haja cumprido os requisitos bastantes à inativação quando da vinda a lume do EC/20, é geralmente aceito ${ }^{8}$ que sobre ele

7 “Curso...", 12a. ed., p.94.

8 Aceito, é certo, pela doutrina tradicional, que entende haver, no caso, apenas uma "expectativa de direito" do servidor à aposentadoria; este não é, entretanto, o nosso particular entendimento sobre o assunto, como já exposto. 
incidirão as exigências feitas inserir no Texto Supremo pela citada Emenda Constitucional; assim, encontrar-se-á na contingência de ter de satisfazer, para aposentar-se com proventos integrais (correspondentes à totalidade de sua remuneração na atividade), aquelas inscritas no art. $8^{\circ}$ da mesma EC/20; particularmente entendemos, todavia, que esse novo regramento só se aplica àqueles que venham a ingressar no serviço público depois de sua edição, descabendo falar-se em "regras de transição" para quem (segundo nossa tese) já adquiriu o direito ao regime de aposentadoria sob o qual logrou aquele ingresso;

- de esclarecer-se, quanto a este particular, que o antigo tempo de serviço do servidor - e contado para fins de aposentadoria segundo as regras então vigentes - será considerado como tempo de contribuição; imperioso também deixar patente que a proibição - contida no art. $40, \S 10$ da Constituição - de contagem de tempo de contribuição "fictício" (o de "licença prêmio" em dobro, como se admitia antes) só vale da edição da Emenda em diante, jamais retroativamente;

- no que respeita ao dever de contribuir para a Previdência, impende reiterar o que já se afirmou: o servidor aposentado, ou o que já adquiriu o direito à aposentadoria, não está, definitivamente, obrigado a voltar ou continuar a contribuir para a previdência social; com efeito, dispõe o art. $3^{\circ}, \S 1^{\circ}$, da referida $E C / 20$, in verbis: “Art. $3^{\circ}$ - É assegurada a concessão de aposentadoria e pensão, a qualquer tempo, aos servidores públicos e aos segurados do regime geral de previdência social, bem como aos seus dependentes que, até a data da publicação desta Emenda, tenham cumprido os requisitos para a obtenção destes benefícios com base nos critérios da legislação então vigente. $-\S 1^{\circ}-\mathrm{O}$ servidor de que trata este artigo, que tenha completado as exigências para aposentadoria integral e que opte por permanecer em atividade fará jús à isenção da contribuição previdenciária até completar as exigências para a aposentadoria contidas no art. $40, \S 1^{\circ}$, III, $a$, da Constituição Federal"; das prescrições transcritas exurgem, límpidas, as seguintes conclusões: 1) a Emenda 20 quis expressamente resguardar o direito adquirido à aposentadoria, até sua promulgação, com base nos critérios da legislação então vigente (cabeça do art. $3^{\circ}$ ); 2 ) concedeu ela (no parágrafo primeiro) uma isenção da contribuição previdenciária àquele servidor que, mesmo tendo adquirido direito à aposentadoria, optasse por continuar no serviço ativo, sujeitando-se às novas regras para aposentação futura; mesmo aqueles servidores que tenham, embora com o direito já adquirido à aposentação (segundo as regras antigas), optado por continuar no serviço ativo, não contribuirão para o sistema previdenciário, vindo a aposentar-se apenas quando vierem a satisfazer as novas exigências constitucionais (do art. 40 , com a redação que the foi dada pela própria EC/20); depois disso, é claro, não teria mais sentido “isentá-los" do encargo;

- respeitantemente aos servidores em atividade, caberia, sem dúvida, questionar a constitucionalidade de uma elevação significativa do quantum da contribuição; afinal, submetendo-se a remuneração desses servidores à incidência de nova contribuição à previdência, bem superior àquela a que estava ele obrigado, finda-se por promover uma inaceitável redução de seus ganhos e, de conseguinte, uma agressão ao princípio constitucional da irredutibilidade remuneratória (mantido pelo Texto Supremo, mesmo após a EC/20); em nome desse princípio nem mesmo se pode 
cogitar da não-revisão periódica da sua remuneração (v. art. 37, X, da Lei Maior); não é de admitir-se a possibilidade da redução dela, seja qual for o artifício utilizado, como bem anotou, a propósito, AYRES BRITTO: “ ... pelo viés da sobre-oneração percentual do desconto previdenciário, todo o pessoal do setor público tem quebrantada a sua garantia constitucional da irredutibilidade. $O$ que a lei não pode fazer diretamente (reduzir vencimentos, proventos e pensões), ela se atreve a fazer transversalmente: a instituição de alíquotas crescentes de contribuição para o fundo comum de previdência social pública" 9 . 